\title{
Space matters: Understanding the real effects of macroeconomic variations in cross-country housing price movements
}

\author{
Kun Duan, Tapas Mishra and Mamata Parhi*
}

\begin{abstract}
Changes in macroeconomic conditions can significantly determine directions and magnitudes of cross-country housing price movements. We demonstrate that such effects are consistently over-estimated when 'spatial frictions' are merely assumed, but are not explicitly modeled in the empirical framework. The extent of over-estimation bias has significant policy implications.
\end{abstract}

Key Words: Macroeconomic adjustments; Spatial frictions; International housing market; Estimation bias; Spatial panel data.

JEL Classifications: C32; E60; E62; R03; R31

${ }^{*}$ Kun Duan: Southampton Business School, University of Southampton, Highfield Campus, Southampton, SO17 1BJ, UK. E-mail: kd2g15@soton.ac.uk; Tapas Mishra: Southampton Business School, University of Southampton, Highfield Campus, Southampton, SO17 1BJ, UK. E-mail: t.k.mishra@soton.ac.uk; Mamata Parhi: Roehampton Business School, London, UK. E-mail: Mamata.Parhi@roehampton.ac.uk.

Acknowledgement: A large part of the work was undertaken at the University of Bath, UK. We sincerely thank the editor, Prof. Pierre-Daniel Sarte for insightful comments and being extremely helpful during the revision process. An initial version of the paper also benefited significantly from the numerous helpful comments from Prof. Philip Arestis. We, however, are solely responsible for possible errors and omissions. 


\section{Introduction}

Spatial attributes are ubiquitous in almost all walks of economic and social lives. The vast literature in economic geography has rigorously highlighted the instrumental role of 'space' ${ }^{1}$ in facilitating spillover effects and learning among economic agents. A well-known prediction from this literature is that a shock in one location is likely to spill over to adjacent locations, albeit with diminished intensity over time. In a cross-country macroeconomic setting, this would mean that policy adjustments in one country could have a ripple effect among countries in proximity if there is significant spatio-temporal correlations. ${ }^{2}$ This imposing feature of 'space' can be exploited to lend a deeper understanding of the relationship between macroeconomic adjustments and dynamic movements in housing prices in a cross-country setting. So far, the growing literature on the subject has only assumed and provided indirect evidence, but not explicitly modeled 'spatial spillovers' (see for instance, Örsal, 2014 and Arestis and Gonzalez-Martinez, 2016, among others). In the current research note, we introduce 'space' in the empirical relationship and provide new results: in the absence of 'spatial spill-over', the impacts of macroeconomic adjustments on housing prices are consistently over-estimated.

Considered from an international perspective, the literature on macroeconomy-housing market interlinkage is nascent. Yet, the sparse contributions have initiated the emergence of a new line of research demonstrating that macroeconomic adjustments can render direct influence on intercountry housing demand and supply. Örsal (2014) showed that a long-run relationship exist between housing prices, interest rates and per capita GDP. Similarly, Arestis and Gonzalez-Martinez (2016) found that manipulation of interest rates and the introduction of new taxes exert direct control over housing demand-supply dynamics. In these and related studies, the possible impacts of spatial frictions are not explicitly modeled, rather these are implicitly assumed. To the best of our knowledge, there is no systematic study to date, which estimates the effects of macroeconomic variations on housing prices in a spatially embedded framework. What exists so far is an indirect evidence - via synchronization of cycles - of a possible correlation of international housing prices over time (see, for instance, Cesa-Bianchi, 2013).

We contribute to the literature by invoking a direct interplay of 'space' in an international macro economy-housing market context. Our investigation involves a sample of OECD countries covering a period of three decades since 1985. To explore further, we plan the rest of the paper as follows. Section 2 presents data, preliminary empirical evidence and estimation strategy. Section 3 presents empirical results including robustness exercise. Finally, Section 4 concludes and contextualizes our main findings in a policy context.

\footnotetext{
${ }^{1}$ Defined in both geographic and relational terms.

${ }^{2}$ In the form of, for instance, the intensity of trade and institutional and socio-cultural-scientific ties, etc.
} 


\section{Data and Estimation}

\subsection{Data characteristics}

We use annual dataset (1985-2015) for 16 OECD countries which share common economic and geographic borders. ${ }^{3}$ Our dependent variable is seasonally adjusted house prices (hpi). The main regressors are personal disposable income $(p d i)$, unemployment rate $(u r)$, current account balance $(c b)$ and various macroeconomic adjustment indicators such as real interest rate (rir), mortgage loan volumes (credit), taxation on dwellings over house prices (tax) and residential investment ( $r$ i $)$. To motivate our empirical construct, we follow recent literature and present (i) evidence of international synchronization of housing price cycles and (ii) spatial distribution of housing price data.

Figure 1: The cross-country average of moving pair-wise correlation for house prices

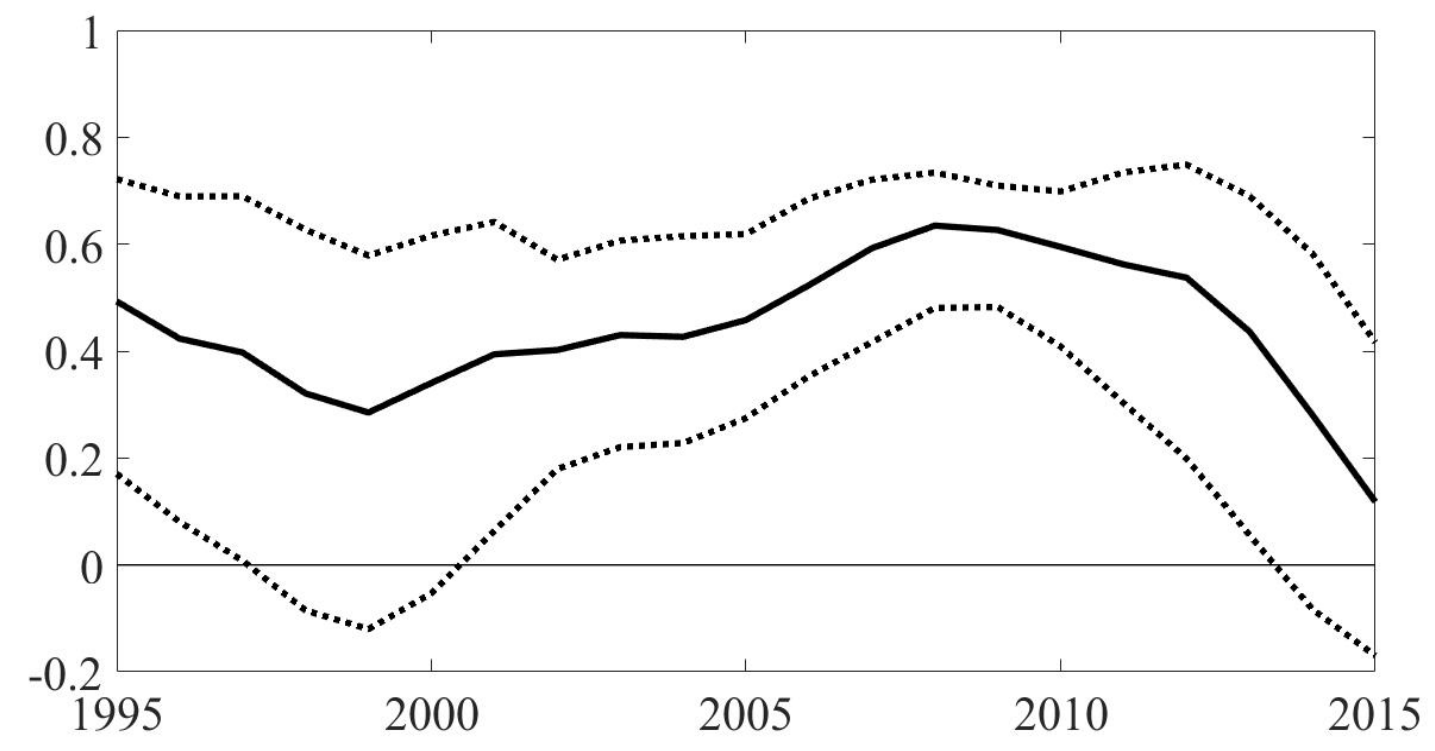

We define average cross-country pair-wise correlation of $x$ for country $i$ by: $\rho_{i}=\left(\sum_{j=1}^{N} \operatorname{COR}\left(x_{i}, x_{j}\right)-1\right) /(N-1)$, where $\operatorname{COR}\left(x_{i}, x_{j}\right)$ is the specific pair-wise correlation of variable $x$ between country $i$ and $j$. Following recommendations in the literature, we have chosen 10 -year rolling window period and find that the correlation of house prices vary between 0.3 to 0.6 for two decades, reaching the peak at 2008 (the outbreak of sub-prime crisis) and witnessing a dramatic fall after 2012 (see Figure 1). Moreover, in Figure 2, the four panels present the correlation for different macroeconomic variables to confirm if macroeconomic adjustment processes are correlated across countries. As the confidence intervals in Figures 1 and 2 confirm, the correlations are large, positive, and statistically significant at 5\% level (except taxation).

\footnotetext{
${ }^{3}$ The countries are Austria, Belgium, Denmark, Finland, France, Germany, Ireland, Italy, Luxembourg, the Netherlands, Norway, Portugal, Spain, Sweden, Switzerland and the United Kingdom.
} 
Figure 2: The cross-country correlations among macroeconomic variables

(a) Real Interest Rate

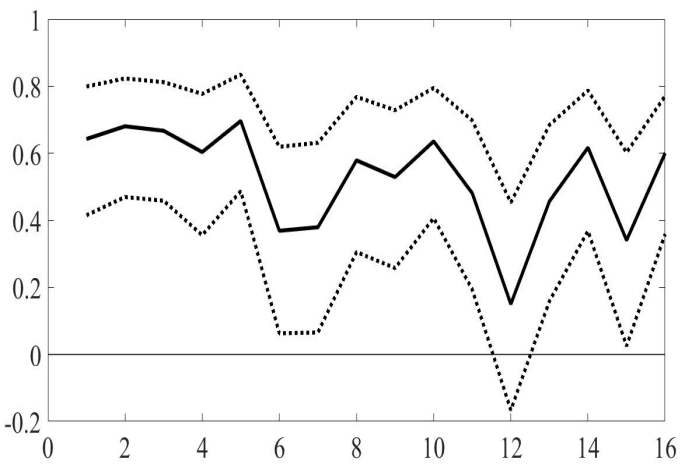

(c) Taxation

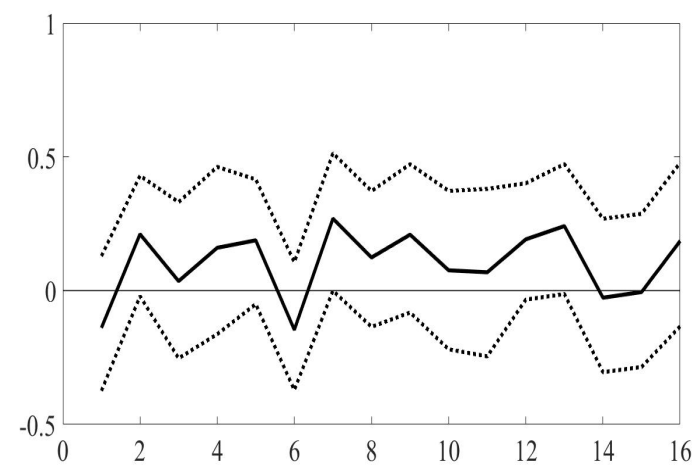

(b) Mortgage Loan Volumes

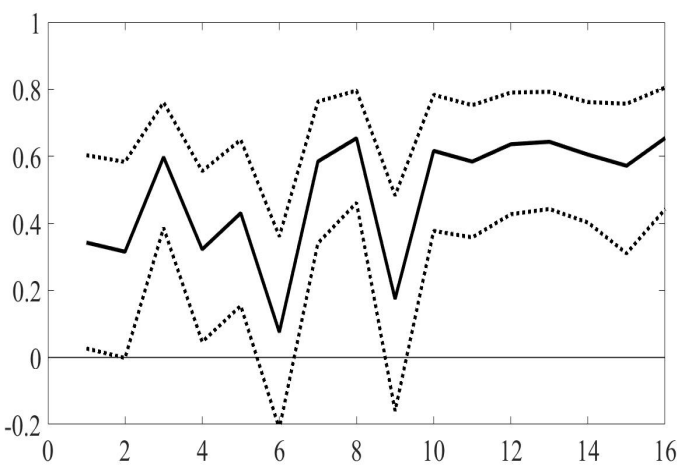

(d) Residential Investment

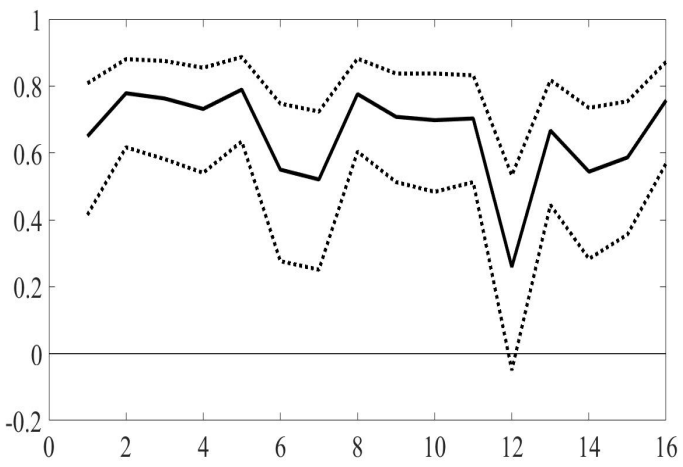

Due to the possibility of spillover effects of macroeconomic policy adjustments, housing prices can also depict significant spatial correlation. Figure 3 presents the spatial distributions of mean and standard deviation of house prices. Expected results emerge: countries with similar patterns in central tendency (i.e., mean and standard deviations) cluster together. This is also confirmed by the estimates of Moran's I statistic depicting significant positive spatial autocorrelation (results are not reported here).

\subsection{Estimation}

To introduce 'space', we describe a theoretical framework that eventually produces the desired reduced-form empirical representation. We follow Arestis and Gonzalez-Martinez (2016) and describe house price equilibrium $\left(h p i^{*}\right)$ in a given country by equation (3). This is a solution to the demand (equation (1)) and supply (equation (2)) interactions for the economy under competitive market assumptions (such as complete information, price clearing and no frictions).

$$
H_{D}=f_{D}\left(h p i^{-}, c b^{-}, p d i^{+}, u r^{-}, \operatorname{rir}_{d}^{-}, \text {credit }^{+}, \operatorname{tax}^{-}\right)
$$


Figure 3: Spatial Distribution of House Prices: Mean and Standard Deviation
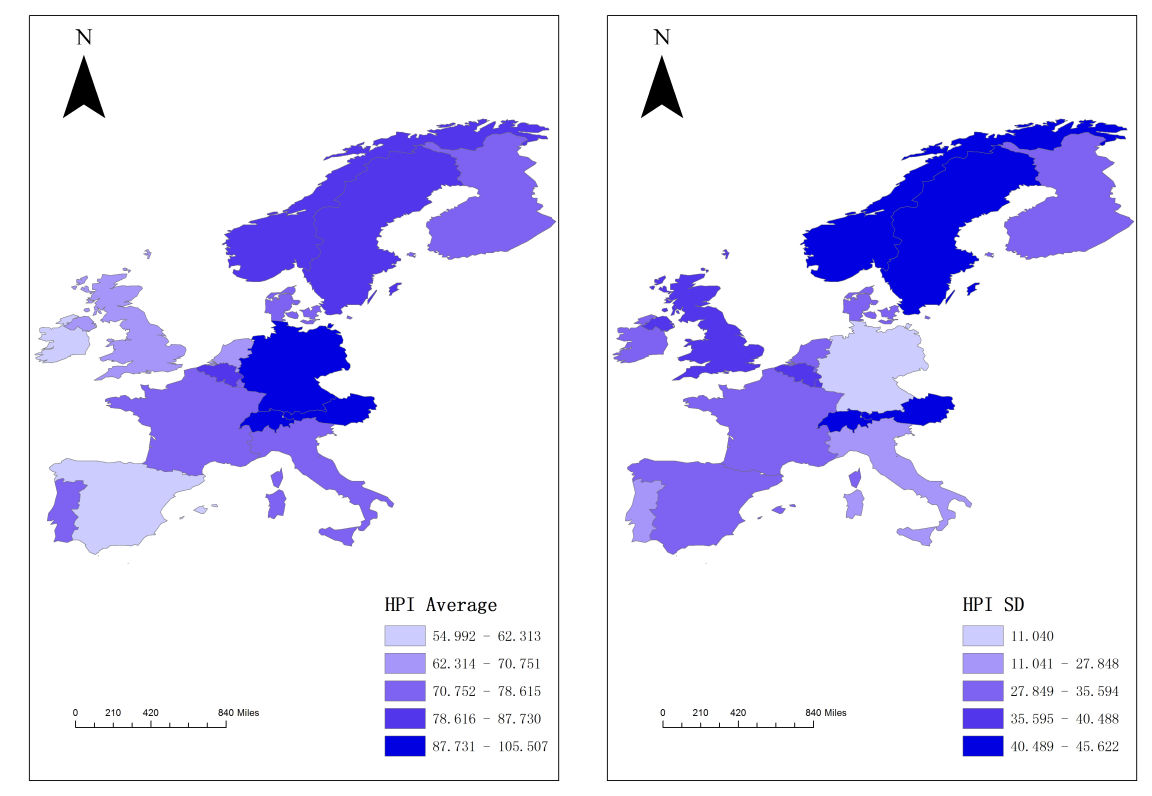

$$
\begin{gathered}
H_{S}=f_{S}\left(h p i^{+}, \operatorname{rir}_{s}^{-}, r r i^{+}\right) \\
h p i^{*}=f_{h p i}\left(c b^{-}, p d i^{+}, u r^{-}, r i r^{-}, c r e d i t^{+}, t a x^{-}, r r i^{-}\right)
\end{gathered}
$$

In practice, the strict assumptions of a competitive market disappear due to the unavoidable presence of information asymmetry and (persistence of) spatial frictions. A partial adjustment model can capture such dynamics and lend to consistent and reliable estimation of parameters. For the purpose, we employ a spatio-temporal partial adjustment model of LeSage and Pace (2009) and estimate the same using dynamic spatial panel method (in particular, Dynamic Spatial Durbin Model, SDM). Following Elhorst (2014), the SDM model is described as:

$h p i_{i t}=\alpha+\beta h p i_{i t-1}+\gamma \sum_{j=1}^{N} W_{i j} h p i_{i t-1}+\rho \sum_{j=1}^{N} W_{i j} h p i_{i t}+\sum_{k=1}^{K} X_{i t} \zeta_{k}+\sum_{k=1}^{K} \sum_{j=1}^{N} W_{i j} X_{j k t} \eta_{k}+\theta_{i}+\nu_{t}+\varepsilon_{i t}$

In equation (4), $i=1, \ldots, N ; t=1, \ldots, T ; k=1, \ldots, K ; i \neq j$. Moreover, $\sum_{j=1}^{N} W_{i j} h p i_{i t}$ and $\sum_{k=1}^{K} \sum_{j=1}^{N} W_{i j} X_{j k t}$ stand for spatial endogenous dependence and spatial exogenous dependence, respectively, whereas $\sum_{k=1}^{K} X_{i t}$ denotes $K$ individual exogenous variables. $\theta_{i}$ and $\nu_{t}$ represent spatial and time specific effects. And finally, error terms, $\varepsilon_{i t} \sim i i d\left(0, \sigma^{2} I_{N}\right)$.

An important feature of equation (4) concerns its ability to distinguish between the within (i.e., direct) and across (i.e., indirect) border effects of the estimated parameters. Moreover, this specification also possesses unique identification strategy of parameters by adding both contemporaneous spatial endogenous and exogenous lags to the empirical construct (see Fingleton and Le Gallo, 2010 for discussions). Recently, Tao and Yu (2012) also stressed that temporal spatial lags of the dependent variable in a SDM model captures 'either policy adjustments or inter-temporal 
budget constraints'. Their omissions may give rise to serious bias in estimations. Note that the coefficient, $W Y_{t-1}$ can be negative because $W Y_{t}$ and $Y_{t-1}$ are jointly positive. An alternative estimation method can also be presented to check if our estimates are sensitive to methodological choice. For this purpose, we also perform a dynamic spatial autoregressive (SAR) estimation of our empirical model. The dynamic SAR model is obtained by removing independent variables and spatial exogenous dependence from equation (4) (where we impose $\zeta_{k}=\eta_{k}=0$ ).

A prior step to estimating both dynamic SDM and SAR involves determination of the order of integration (' $\mathrm{d}$ ') of the relevant variables (because regression with non-stationary variables can give rise to spurious estimates). We have performed (cross-section dependent) panel unit root tests ${ }^{4}$ and could not reject the null hypothesis of a panel unit root at both $5 \%$ and $1 \%$ significance levels. Following this, we first-differenced all variables before estimation. To denote, we have put a prefix 'd' for each variable.

\section{Empirical Results}

\subsection{Model choice}

We need to determine first, whether a fixed effects or a random effects model is suitable for our data. Using Hausman specification test, we find that the estimated test statistic, $965.20>$ the critical value of 25.00 at $5 \%$ level of significance indicating that a fixed effects model is the preferable specification. We determine next if a dynamic SDM is more suitable to our data than a static SDM. We tested the null hypothesis $\left(H_{0}\right)$ that $\beta=\gamma=0$. A likelihood ratio $(L R)$ in this regard produced $L R=2 \times(-1142.232+1284.196)=283.928$, which is greater than the critical value of 5.99 at $5 \%$ significance level, indicating a strong rejection of the null hypothesis of a static SDM. Similarly, with regard to the SAR model, the Hausman specification test favored fixed effects model as well because the estimated test statistic (34.420) > the critical value (15.510) at 5\% significance level. Furthermore, the estimated $L R$ test statistic (281.728) is found to be greater than the critical value (5.99) at $5 \%$ level of significance leading us to choose a dynamic SAR model for our data. In Tables 2 and 3 we report the results from fixed effects dynamic SDM and SAR estimations.

\subsection{Quantification of spillover effects}

Table 1 presents the main results (the benchmark case). Table 2 reports estimations from robustness exercise. In Table 1, columns 1 and 4 report estimates from the non-spatial panel method (The OLS regression). Results in columns 2 and 5 correspond to the dynamic SDM model, whereas columns 3 and 6 correspond to results from dynamic SAR estimations. The regressors in columns 1 - 3 include both general and macroeconomic policy variables, whereas columns 4 - 6 omit the macroeconomic policy variables (in particular, real interest rates (rri) and taxation on dwellings over housing prices $(\operatorname{tax})$ ). In all tables, the results in "Main" section (results in the upper panel)

\footnotetext{
${ }^{4}$ The results are available with the authors upon request.
} 
correspond to without spatial spill-over effects or within-border effects, whereas "Wx" section of the results (results in the lower panel) denotes spatial spill-over effects or across-the-border effects.

Several interesting patterns emerge from Table 1 . With the exception of residential investment (rri) (where we have an $a$-theoretical negative coefficient), all variables produce expected theoretical signs. The negative coefficient for rri may occur because rri tends to change over time and may exert a negative impact on housing prices in the short term and a positive impact in the long term (Arestis and Gonzalez-Martinez, 2016). Moreover, consistent with the literature, we find that macroeconomic variables, viz., tax, interest rate, and current account balance exert significant effects on housing prices. However, we observe that - in the absence of spatial spill-over effects and/or macroeconomic policy factors - the estimated effects on house prices (in absolute value) suffer from estimation bias. For instance, in column 1 (the non-spatial model), the estimated effects of taxation are 0.023 and 0.028 point smaller than the estimated effects in column 2 (the dynamic SDM) and column 3 (the dynamic SAR model) in absolute terms, respectively. Similarly, considering columns $4-6$, we also find an overestimation bias for the unemployment variable. In addition, we observe that the temporal lag of the housing prices ( $L . d h p i$ ) is positive regardless

of the specification of the spatial model (in columns 2, 3, 5 and 6). This coefficient measures the dynamic adjustment of housing prices, thanks to the nature of partial adjustment owing to incomplete information and frictions in the market. We also find clear evidence of positive spatial autocorrelation of housing prices as shown by the significant positive effects of contemporaneous spatial lag (Wdhpi).

We now move to the ' $W x^{\prime}$ section of the results (lower panel figures) in Table 1 (i.e., results with across-the-border effects). In column 2, we find that the estimated effects of the current account balance and personal disposable income are 0.589 and -0.675 , respectively. These are greater than the counterparts in column 5 in absolute value (i.e., the results after omitting macroeconomic policy variables). Besides, as a guide to the model selection, the observed $R^{2}$ (in column 2 ) is the highest between spatial and non-spatial models. This indicates that inclusion of spatial spillover effects and macroeconomic policy interventions as regressors in the dynamic SDM estimations gain better explanatory power and thus, these variables are of paramount importance to modeling housing price movements across countries.

\subsubsection{Robustness}

To check the sensitivity of our results, we replace residential investment ( $r r i)$ by a measure of total factor productivity (TFP) after excluding construction costs. Moro and Nuño (2011) argue that the conventional estimates of $r r i$ are dominated by the construction costs of residential buildings. Therefore, separating out its effects from rri and using the new measure can mitigate measurement bias in the estimation. The authors construct a TFP that accounts for construction costs and claim that this measure can exert significant positive effects on housing prices. We follow Moro and Nuño (2011) and re-estimate equation (4) by replacing rri with TFP.

Table 2 presents results from this exercise. We find that TFP (the variable, $d t f p$ ) affects inter- 
Table 1: Dynamic SDM and SAR Results: Benchmark Case

\begin{tabular}{|c|c|c|c|c|c|c|}
\hline Variables & col.(1) & col.(2) & col.(3) & col.(4) & col.(5) & col.(6) \\
\hline \multicolumn{7}{|l|}{ Main } \\
\hline \multirow[t]{2}{*}{$\mathrm{dcb}$} & -0.117 & -0.024 & -0.043 & -0.123 & -0.034 & -0.033 \\
\hline & $(0.100)$ & (0.079) & $(0.080)$ & (0.098) & (0.078) & (0.078) \\
\hline \multirow[t]{2}{*}{ dpdi } & $0.414^{* * *}$ & 0.123 & 0.078 & $0.455^{* * *}$ & $0.143^{*}$ & 0.093 \\
\hline & $(0.103)$ & $(0.083)$ & $(0.081)$ & $(0.103)$ & $(0.083)$ & $(0.081)$ \\
\hline \multirow[t]{2}{*}{ dur } & $-0.982^{* * *}$ & $-0.931^{* * *}$ & $-0.664^{* * *}$ & $-0.973^{* * *}$ & $-0.921^{* * *}$ & $-0.674^{* * *}$ \\
\hline & $(0.204)$ & $(0.183)$ & $(0.157)$ & $(0.204)$ & $(0.184)$ & $(0.156)$ \\
\hline \multirow[t]{2}{*}{ dcredit } & $0.056^{* * *}$ & 0.007 & -0.002 & $0.063^{* * *}$ & 0.007 & 0.000 \\
\hline & $(0.021)$ & $(0.017)$ & $(0.017)$ & $(0.021)$ & $(0.017)$ & $(0.017)$ \\
\hline \multirow[t]{2}{*}{ drri } & $0.456^{* * *}$ & $0.256^{* * *}$ & $0.270^{* * *}$ & $0.462^{* * *}$ & $0.249^{* * *}$ & $0.270^{* * *}$ \\
\hline & $(0.052)$ & $(0.041)$ & $(0.041)$ & $(0.053)$ & $(0.042)$ & $(0.041)$ \\
\hline \multirow[t]{2}{*}{ dtax } & $-0.052^{* * *}$ & $-0.029^{* *}$ & $-0.024^{* *}$ & & & \\
\hline & $(0.016)$ & $(0.012)$ & $(0.012)$ & & & \\
\hline \multirow[t]{2}{*}{ drir } & -0.075 & -0.043 & -0.086 & & & \\
\hline & $(0.083)$ & $(0.066)$ & $(0.064)$ & & & \\
\hline \multirow[t]{2}{*}{ L.dhpi } & & $0.592^{* * *}$ & $0.602^{* * *}$ & & $0.605^{* * *}$ & $0.611^{* * *}$ \\
\hline & & $(0.034)$ & $(0.035)$ & & $(0.034)$ & $(0.035)$ \\
\hline C & $\begin{array}{l}1.451^{* * *} \\
(0.339)\end{array}$ & & & $\begin{array}{l}1.317^{* * *} \\
(0.340)\end{array}$ & & \\
\hline \multicolumn{7}{|l|}{ Wx } \\
\hline \multirow[t]{2}{*}{ Wdcb } & & $0.589^{* *}$ & & & $0.516^{* *}$ & \\
\hline & & $(0.250)$ & & & $(0.245)$ & \\
\hline \multirow[t]{2}{*}{ Wdpdi } & & $-0.675^{* * *}$ & & & $-0.492^{* *}$ & \\
\hline & & $(0.218)$ & & & $(0.204)$ & \\
\hline \multirow[t]{2}{*}{ Wdur } & & 0.265 & & & 0.384 & \\
\hline & & $(0.380)$ & & & $(0.377)$ & \\
\hline \multirow[t]{2}{*}{ Wdcredit } & & 0.035 & & & 0.015 & \\
\hline & & $(0.044)$ & & & $(0.044)$ & \\
\hline \multirow[t]{2}{*}{ Wdrri } & & $0.297^{* * *}$ & & & $0.207^{*}$ & \\
\hline & & $(0.114)$ & & & (0.109) & \\
\hline \multirow[t]{2}{*}{ Wdtax } & & $-0.064^{* *}$ & & & & \\
\hline & & $(0.031)$ & & & & \\
\hline Wdrir & & $\begin{array}{l}-0.131 \\
(0.157)\end{array}$ & & & & \\
\hline \multirow[t]{2}{*}{ Wdhpi } & & $0.343^{* * *}$ & $0.449^{* * *}$ & & $0.399^{* * *}$ & $0.456^{* * *}$ \\
\hline & & $(0.076)$ & $(0.058)$ & & $(0.071)$ & $(0.058)$ \\
\hline \multirow[t]{2}{*}{ L.Wdhpi } & & $-0.282^{* * *}$ & $-0.407^{* * *}$ & & $-0.282^{* * *}$ & $-0.417^{* * *}$ \\
\hline & & $(0.085)$ & $(0.070)$ & & $(0.085)$ & $(0.070)$ \\
\hline \multirow[t]{2}{*}{ Residual variance $\left(\sigma^{2}\right)$} & & $8.215^{* * *}$ & $8.566^{* * *}$ & & $8.403^{* * *}$ & $8.676^{* * *}$ \\
\hline & & $(0.524)$ & $(0.547)$ & & $(0.537)$ & $(0.555)$ \\
\hline Country Fixed Effects & Included & Included & Included & Included & Included & Included \\
\hline Observartions & 480 & 464 & 464 & 480 & 464 & 464 \\
\hline$R^{2}$ & 0.406 & 0.656 & 0.618 & 0.391 & 0.640 & 0.609 \\
\hline Number of Countries & 16 & 16 & 16 & 16 & 16 & 16 \\
\hline
\end{tabular}

Note: The results correspond to fixed-effects estimation. * Significance at $10 \%$ level; ${ }^{* *}$ Significance at $5 \%$ level; *** Significance at 1\% level; Standard errors are in parentheses. Columns 1 and 4 are for the non-spatial panel model; columns 2 and 5 are for the dynamic SDM model; Columns 3 and 6 are for the dynamic SAR model. 
national house prices positively and significantly. The nature of the impacts remain unchanged across non-spatial and dynamic spatial panel models. Similar conclusions hold for the dynamic SDM and the dynamic SAR models in turn. Furthermore, the effects of macroeconomic variables, such as unemployment rate, real interest rates and taxation on dwellings over house prices are also consistent with the results presented in Table 1. Importantly, we also detect positive spatial spill-over effects of TFP on housing prices (these are 0.460 in column 8 and 0.452 in column 11, respectively). The results are broadly consistent with Table 1.

\section{Conclusions}

Theory and empirics related to the intervention of macroeconomic policy in international housing price movements are of recent origin. We argued that while macroeconomic adjustment process can impact (international) housing market equilibrium, exclusion of spatial spill-over effects from the empirical model may give rise to over-estimation bias. Because 'space' can act as a medium where agents engage in learning and adaptation, omitting this attribute from the empirical construct may result in an overemphasis of the role of macroeconomic policy instruments in regulating (international) housing-market equilibrium. 
Table 2: Results from Robustness Exercise

\begin{tabular}{|c|c|c|c|c|c|c|}
\hline Variables & col.(7) & col.(8) & col.(9) & col.(10) & col.(11) & col.(12) \\
\hline \multicolumn{7}{|l|}{ Main } \\
\hline \multirow[t]{2}{*}{$\mathrm{dcb}$} & -0.329 & -0.187 & -0.114 & -0.347 & -0.101 & -0.096 \\
\hline & $(0.290)$ & $(0.200)$ & $(0.200)$ & $(0.300)$ & $(0.210)$ & $(0.210)$ \\
\hline \multirow[t]{2}{*}{ dpdi } & $0.405^{*}$ & 0.048 & -0.022 & $0.526^{* *}$ & 0.084 & 0.001 \\
\hline & $(0.220)$ & $(0.170)$ & $(0.160)$ & $(0.220)$ & $(0.170)$ & $(0.170)$ \\
\hline \multirow[t]{2}{*}{ dur } & $-1.330^{* * *}$ & $-0.736^{* * *}$ & $-0.655^{* * *}$ & $-1.254^{* * *}$ & $-0.933^{* * *}$ & $-0.786^{* * *}$ \\
\hline & $(0.350)$ & $(0.280)$ & $(0.250)$ & $(0.350)$ & $(0.280)$ & $(0.250)$ \\
\hline \multirow[t]{2}{*}{ dcredit } & 0.074 & -0.026 & -0.030 & 0.080 & -0.021 & -0.026 \\
\hline & $(0.051)$ & $(0.036)$ & $(0.036)$ & $(0.052)$ & $(0.037)$ & (0.037) \\
\hline \multirow[t]{2}{*}{$\mathrm{dtfp}$} & $0.257^{* * *}$ & $0.252^{* * *}$ & $0.287^{* * *}$ & $0.280^{* * *}$ & $0.268^{* * *}$ & $0.294^{* * *}$ \\
\hline & $(0.097)$ & $(0.073)$ & $(0.074)$ & $(0.098)$ & $(0.074)$ & $(0.075)$ \\
\hline \multirow[t]{2}{*}{ dtax } & $-0.123^{* * *}$ & $-0.061^{* *}$ & -0.040 & & & \\
\hline & $(0.044)$ & $(0.031)$ & (0.033) & & & \\
\hline \multirow[t]{2}{*}{ drir } & -0.044 & $-0.818^{* * *}$ & $-0.547^{* *}$ & & & \\
\hline & $(0.310)$ & $(0.270)$ & $(0.230)$ & & & \\
\hline \multirow[t]{2}{*}{ L.dhpi } & & $0.702^{* * *}$ & $0.781^{* * *}$ & & $0.717^{* * *}$ & $0.787^{* * *}$ \\
\hline & & $(0.070)$ & $(0.072)$ & & $(0.071)$ & $(0.072)$ \\
\hline C & $\begin{array}{l}2.611^{* * *} \\
(0.650)\end{array}$ & & & $\begin{array}{l}2.413^{* * *} \\
(0.660)\end{array}$ & & \\
\hline \multicolumn{7}{|l|}{ Wx } \\
\hline Wdcb & & $\begin{array}{l}0.401 \\
(0.430)\end{array}$ & & & $\begin{array}{l}0.412 \\
(0.430)\end{array}$ & \\
\hline Wdpdi & & $\begin{array}{l}-0.488 \\
(0.410)\end{array}$ & & & $\begin{array}{l}-0.605 \\
(0.400)\end{array}$ & \\
\hline Wdur & & $\begin{array}{l}-0.026 \\
(0.630)\end{array}$ & & & $\begin{array}{l}0.038 \\
(0.640)\end{array}$ & \\
\hline Wdcredit & & $\begin{array}{l}-0.131 \\
(0.110)\end{array}$ & & & $\begin{array}{l}-0.088 \\
(0.110)\end{array}$ & \\
\hline Wdtfp & & $\begin{array}{l}0.460^{* * *} \\
(0.178)\end{array}$ & & & $\begin{array}{l}0.452^{* *} \\
(0.181)\end{array}$ & \\
\hline Wdtax & & $\begin{array}{l}0.086 \\
(0.091)\end{array}$ & & & & \\
\hline Wdrir & & $\begin{array}{l}0.679 \\
(0.470)\end{array}$ & & & & \\
\hline Wdhpi & & $\begin{array}{l}0.372^{* * *} \\
(0.100)\end{array}$ & $\begin{array}{l}0.498^{* * *} \\
(0.081)\end{array}$ & & $\begin{array}{l}0.348^{* * *} \\
(0.110)\end{array}$ & $\begin{array}{l}0.480^{* * *} \\
(0.083)\end{array}$ \\
\hline L.Wdhpi & & $\begin{array}{l}-0.217 \\
(0.150)\end{array}$ & $\begin{array}{l}-0.500^{* * *} \\
(0.110)\end{array}$ & & $\begin{array}{l}-0.226 \\
(0.140)\end{array}$ & $\begin{array}{l}-0.521^{* * *} \\
(0.110)\end{array}$ \\
\hline Residual variance $\left(\sigma^{2}\right)$ & & $\begin{array}{l}5.826^{* * * *} \\
(0.660)\end{array}$ & $\begin{array}{l}6.602^{* * *} \\
(0.750)\end{array}$ & & $\begin{array}{l}6.407^{* * *} \\
(0.720)\end{array}$ & $\begin{array}{l}6.957^{* * *} \\
(0.790)\end{array}$ \\
\hline Country Fixed Effects & Included & Included & Included & Included & Included & Included \\
\hline Observartions & 150 & 140 & 140 & 150 & 140 & 140 \\
\hline$R^{2}$ & 0.315 & 0.699 & 0.604 & 0.274 & 0.670 & 0.602 \\
\hline Number of Countries & 10 & 10 & 10 & 10 & 10 & 10 \\
\hline
\end{tabular}

Note: The results correspond to fixed-effects estimation. ${ }^{*}$ Significance at $10 \%$ level; ${ }^{* *}$ Significance at $5 \%$ level; $* * *$ Significance at $1 \%$ level; standard errors in parentheses. Columns 7 and 10 are for the non-spatial panel model; Columns 8 and 11 are for the dynamic SDM model; Columns 9 and 12 are for the dynamic SAR model. 


\section{References}

1. Arestis, P. and Gonzalez-Martinez, A.R. (2016), "House prices and current account imbalances in OECD countries", International Journal of Finance $\mathcal{E}$ Economics, 21(1), pp.58-74.

2. Cesa-Bianchi, A. (2013), "Housing cycles and macroeconomic fluctuations: A global perspective", Journal of International Money and Finance, 37, pp.215-238.

3. Elhorst, J.P. (2014), Spatial panel models. in "Handbook of Regional Science", Springer Berlin Heidelberg, pp.1637-1652.

4. Lee, L.F. and Yu, J. (2010), "A spatial dynamic panel data model with both time and individual fixed effects", Econometric Theory, 26(2), pp.564-597.

5. LeSage, J. and Pace, R.K. (2009), Introduction to Spatial Econometrics. Boca Raton, FL: CRC Press.

6. Moro, A. and Nuño, G. (2012), “Does total-factor productivity drive housing prices? A growth-accounting exercise for four countries", Economics Letters, 115(2), pp.221-224.

7. Örsal, D.D.K. (2014), "Do the global stochastic trends drive the real house prices in OECD countries?", Economics Letters, 123(1), pp.9-13.

8. Tao, J. and Yu, J. (2012), “The spatial time lag in panel data models”, Economics Letters, 117(3), pp. 544-547. 